\title{
Cholic acid for primary bile acid synthesis defects: a life-saving therapy allowing a favorable outcome in adulthood
}

\author{
Emmanuel Gonzales ${ }^{1,2,311 \dagger}$, Lorenza Matarazzo ${ }^{4 \dagger}$, Stéphanie Franchi-Abella ${ }^{2,5}$, Alain Dabadie ${ }^{6}$, Joseph Cohen ${ }^{1}$, \\ Dalila Habes ${ }^{1}$, Sophie Hillaire ${ }^{7}$, Catherine Guettier ${ }^{2,8}$, Anne-Marie Taburet ${ }^{9}$, Anne Myara ${ }^{10}$ \\ and Emmanuel Jacquemin ${ }^{1,2,3^{*}}$ (1)
}

\begin{abstract}
Background: Oral cholic acid (CA) replacement has been shown to be an effective therapy in children with primary bile acid synthesis defects, which are rare and severe genetic liver diseases. To date there has been no report of the effects of this therapy in children reaching adulthood. The aim of the study was to evaluate the long-term effectiveness and safety of CA therapy.

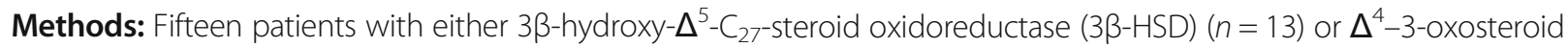
$5 \beta$-reductase $\left(\Delta^{4}-3\right.$-oxo-R) $(n=2)$ deficiency confirmed by mass spectrometry and gene sequencing received oral $C A$ and were followed prospectively.

Results: The median age at last follow-up and the median time of follow-up with treatment were 24.3 years (range: 15. 3-37.2) and 21.4 years (range: 14.6-24.1), respectively. At last evaluation, physical examination findings and blood laboratory test results were normal in all patients. Liver sonograms were normal in most patients. Mean daily CA dose was $6.9 \mathrm{mg} / \mathrm{kg}$ of body weight. Mass spectrometry analysis of urine showed that excretion of the atypical metabolites remained low or traces in amount with CA therapy. Liver fibrosis scored in liver biopsies or assessed by elastography in 14 patients, after 10 to 24 years with CA therapy, showed a marked improvement with disappearance of cirrhosis (median score < F1; range: F0-F2). CA was well tolerated in all patients, including five women having 10 uneventful pregnancies during treatment.
\end{abstract}

Conclusions: Oral CA therapy is a safe and effective long-term treatment of 3 $\beta$-HSD and $\Delta^{4}$-3-oxo-R deficiencies and allows affected children to reach adulthood in good health condition without the need for a liver transplantation.

Keywords: Bile acid, Genetic cholestasis, AKR1D1, HSD3B7

\section{Background}

Inborn errors of primary bile acid synthesis are rare inherited autosomal recessive disorders. The most frequent defects are the $3 \beta-\Delta^{5}$-hydroxy- $\mathrm{C}_{27}$-steroid oxidoreductase (3 $\beta$-HSD) deficiency (OMIM 607765) which

\footnotetext{
* Correspondence: emmanuel.jacquemin@aphp.fr

†Emmanuel Gonzales and Lorenza Matarazzo contributed equally to this work.

${ }^{1}$ Pediatric Hepatology and Pediatric Liver Transplantation Unit, National Reference Centre for rare pediatric liver diseases and Filfoie, Hôpital Bicêtre, Assistance Publique-Hôpitaux de Paris, Paris, France

${ }^{2}$ Faculty of Medicine Paris - Sud, University Paris - Sud / Paris - Saclay, Paris, France

Full list of author information is available at the end of the article
}

is due to mutations in HSD3B7; and to a lesser extent the $\Delta^{4}$-3-oxosteroid- $5 \beta$-reductase $\left(\Delta^{4}-3\right.$-oxo- $\left.\mathrm{R}\right)$ deficiency (OMIM 235555) due to mutations in AKR1D1 [1-7]. These defects in enzymes catalyzing key reactions in the formation of the primary bile acids (BA), namely cholic acid (CA) and chenodeoxycholic acid (CDCA) in human, lead to an inadequate synthesis of primary BA that are critical for bile formation and to the production and the accumulation of atypical and hepatotoxic BA intermediates [8-11]. These deficiencies are most commonly manifest in neonates or infants as cholestasis and can progress to early cirrhosis and liver failure unless treated $[1,2,7,9,10]$. Absence of pruritus, normal

(C) The Author(s). 2018 Open Access This article is distributed under the terms of the Creative Commons Attribution 4.0 International License (http://creativecommons.org/licenses/by/4.0/), which permits unrestricted use, distribution, and 
serum $\gamma$-glutamyltransferase (GGT) activity, and normal or low total serum bile acid concentration are diagnostic features of these conditions [12]. Specific diagnosis is based on mass spectrometry (MS) analysis of urinary bile acids showing typical bile acid profiles and on the identification of disease-causing mutations in HSD3B7 or in AKR1D1 [1-10]. Oral primary bile acid replacement by CA or CDCA is required for these defects in order to restore bile flow and to down-regulate endogenous bile acid synthesis $[9,10,13-16]$. CA is the major primary bile acid in humans and is now recognized as the bile acid of choice since it is neither hepatotoxic nor embryotoxic/teratogenic, and is effective therapy for $3 \beta$-HSD and $\Delta^{4}-3$-oxo-R deficiencies $[9,10,14,16-19]$. $\mathrm{CA}$ is the only primary BA having a marketing authorization in the USA [20] and in Europe [21] in these two indications. Prolonged oral CA therapy is considered safe and lifesaving during childhood as it leads to normalization of clinical features, serum liver biochemistry and liver imaging, together with a substantial improvement of mass spectrometry bile acid profiles and liver histology [14, 16-19]. However, published data concerning the long-term outcome of such patients treated with oral CA and reaching adulthood are lacking. In this study, we updated the follow-up, after around 20 years of CA therapy, of a previously reported cohort of 15 patients with $3 \beta$-HSD or $\Delta^{4}-3$-oxo-R deficiencies [14], most of whom having now reached adulthood. The data confirm the favorable outcome with treatment, mainly the decrease in liver fibrosis, and show that CA therapy should guarantee a normal quality of life during adulthood.

\section{Methods}

\section{Patients and study design}

the 15 patients (13 with $3 \beta$-HSD deficiency [patients $1-$ 13 , families $\mathrm{A}-\mathrm{I}]$ and two with $\Delta 4-3$-oxo-R deficiency [patients 14, 15, family J]), prospectively followed from 1993 to August 2007 and reported in 2009 [14] were again followed prospectively during CA therapy from August 2007 to 2017 (Table 1). This new 10-year period of time of follow-up analysis represents the basis of the study. As previously described, the follow-up evaluations were performed every year and included: 1) physical examination at least once a year; 2) blood liver biochemistry tests including alpha-fetoprotein and total serum bile acids; 3) abdominal ultrasonography; 4) urine bile acid analyses by gas chromatography/mass spectrometry (GC-MS). Bile acid analyses in urine samples were

Table 1 Characteristics of 15 patients diagnosed with either a $3 \beta$-hydroxy- $\Delta^{5}-C_{27}$-steroid oxidoreductase deficiency or a $\Delta^{4}-3$ oxosteroid $5 \beta$-reductase deficiency and who received long-term therapy with cholic acid

\begin{tabular}{|c|c|c|c|c|c|c|}
\hline \multirow{2}{*}{$\begin{array}{l}\text { Patient } \\
\text { (Family) }\end{array}$} & \multirow[t]{2}{*}{ Sex } & \multirow{2}{*}{$\begin{array}{l}\text { Age at } \\
\text { CA } \\
\text { therapy initiation } \\
\text { (years) }\end{array}$} & \multirow{2}{*}{$\begin{array}{l}\text { Duration } \\
\text { of CA therapy } \\
\text { (years) }\end{array}$} & \multirow{2}{*}{$\begin{array}{l}\text { Age at } \\
\text { last } \\
\text { follow-up } \\
\text { (years) }\end{array}$} & \multicolumn{2}{|c|}{ Daily dose of CA at last follow-up } \\
\hline & & & & & $\mathrm{mg} \cdot \mathrm{kg}^{-1}$ & $\mathrm{mg}$ \\
\hline \multicolumn{7}{|c|}{ 3ß-HSD deficiency } \\
\hline $1(\mathrm{~A})$ & M & 3.9 & 24.1 & 28.0 & 6.1 & 500 \\
\hline 2 (B) & $\mathrm{F}$ & 4.3 & 24.1 & 28.4 & 6.9 & 450 \\
\hline $3(C)$ & $\mathrm{F}$ & 7.8 & 24.1 & 31.8 & 5.8 & 350 \\
\hline 4 (D1) & $\mathrm{F}$ & 4.3 & 24.1 & 28.3 & 7.5 & 400 \\
\hline 5 (D2) & $\mathrm{F}$ & 0.6 & 14.6 & 15.3 & 6.5 & 300 \\
\hline $6(\mathrm{E} 1)$ & M & 5.2 & 24.1 & 29.3 & 6.4 & 500 \\
\hline $7(\mathrm{E} 2)$ & $\mathrm{F}$ & 13.1 & 24,1 & 37.2 & 8.3 & 500 \\
\hline $8(F)$ & M & 2.3 & 21.9 & 24.3 & 8.4 & 400 \\
\hline $9(\mathrm{G} 1)$ & $\mathrm{F}$ & 2.3 & 21.4 & 23.8 & 8.3 & 450 \\
\hline $10(\mathrm{G} 2)$ & $\mathrm{F}$ & 11.6 & 21,4 & 33.1 & 9.6 & 500 \\
\hline $11(H)$ & $\mathrm{F}$ & 0.8 & 20.1 & 20.9 & 5.5 & 300 \\
\hline $12(\mid 1)$ & M & 5.1 & 16.2 & 21.3 & 4.8 & 350 \\
\hline $13(12)$ & $\mathrm{F}$ & 0.3 & 15.5 & 15.8 & 3.4 & 300 \\
\hline \multicolumn{7}{|c|}{$\Delta^{4}-3-0 \times 0-R$ deficiency } \\
\hline $14(\mathrm{~J} 1)$ & $\mathrm{F}$ & 0.7 & 20.0 & 20.8 & 7.8 & 400 \\
\hline $15(J 2)$ & $\mathrm{F}$ & 0.7 & 20.0 & 20.8 & 7.5 & 400 \\
\hline Median & & 3.9 & 21.4 & 24.3 & 6.9 & 400 \\
\hline Range & & $0.3-13.1$ & $14.6-24.1$ & $15.3-37.2$ & $3.4-9.6$ & $300-500$ \\
\hline
\end{tabular}

a, The numbering of the patients refers to a previous reference reporting in details on demographics and genetic characteristics and on the initial symptoms of

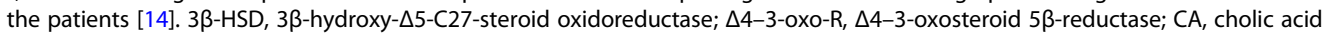


performed as previously described [14] and predominant specific atypical bile acids were determined in urine and expressed as a percentage of total urinary bile acids (physiological plus atypical, in $\mu \mathrm{mol} / \mathrm{mmol}$ creatinine). In the $3 \beta$-HSD deficiency, $3 \beta$-hydroxylated- $\Delta^{5}$ derivatives were assayed whereas in $\Delta^{4}-3$-oxo- $R$ deficiency, 3-oxo- $\Delta^{4}$ derivatives were assayed. In addition, liver biopsy and/or liver elastography (Transient eslastography (Fibroscan) (TE), supersonic shear imaging (SSI), or acoustic radiation force impulse (ARFI) technologies) were performed when indicated and according to patient availability. Liver biopsy specimens were analyzed by the same pathologist (C. G.) and compared to previous biopsies. Portal fibrosis and activity were scored according to the grading system of Metavir, and severity and localization of cholestasis were assessed as previously described for these patients [14]. Data of the liver elastography measurements with TE, SSI, or ARFI technologies were used to estimate liver fibrosis. Because none of these methods have been validated in hereditary defects of primary bile acid synthesis, we chose cut-off values for fibrosis staging (F0-F4) previously reported in chronic liver diseases: 1) The cut off values of TE [22] were: F1 $\geq 6.5, F 2 \geq 8.1, F 3 \geq 10.8, F 4 \geq 13.4 ; 2$ ) The cut off values of SSI [23] were: F1 $\geq 7.5, F 2 \geq 8.04$, F3 $\geq 9.27$, $\mathrm{F} 4 \geq 11.12$. For ARFI, a value $<1.207 \mathrm{~m} / \mathrm{s}$ was considered normal (F0) [24]. Quality of life, social status and professional activity of the patients were assessed by history taking at each clinic visit in our centre.

\section{Treatment}

From 1993 to August 2007, patients received cholic acid as previously reported [14]. Since August 2007, patients received cholic acid (Orphacol, Laboratoires CTRS, Boulogne-Billancourt, France) in two divided doses with $50 \mathrm{mg}$ and/or $250 \mathrm{mg}$ capsules [21]. At this date, the mean daily dose of CA was $6.3 \mathrm{mg} / \mathrm{kg}$ and $5.3 \mathrm{mg} / \mathrm{kg}$ in $3 \beta$-HSD deficiency and $\Delta^{4}-3$-oxo- $\mathrm{R}$ deficiency patients, respectively [14]. One patient with $\Delta^{4}-30 x o-R$ deficiency (patient 14) was still receiving daily $4 \mathrm{mg} / \mathrm{kg}$ of UDCA $(200 \mathrm{mg} / \mathrm{d})$ given separately from CA. This small amount of UDCA was necessary in this patient to maintain normal serum liver biochemistry tests, which were otherwise slightly abnormal. Doses of CA were thereafter adapted individually based upon the results of the follow-up urinary bile acid analyses by GC-MS and serum liver tests. The dosage of $500 \mathrm{mg} /$ day, corresponding to the physiologic daily synthesis rate for primary bile acids in healthy adults [8], was considered as a maximum.

\section{Results}

The median age at last follow-up and the median time of follow-up with treatment were 24.3 years (range:
15.3-37.2) and 21.4 years (range: 14.6-24.1), respectively (Table 1). At last evaluation, physical examination findings and blood laboratory test (liver tests, alphafetoprotein, prothrombin time, factor $\mathrm{V}$, albumin, bile acids, and fat-soluble vitamins) were normal in all patients. Growth in weight and height were within the normal range in all patients. Areflexia or decreased tendon reflexes observed after 5 years with CA therapy in patients 2, 3, 6 and 7 was still observed in these four patients at last follow-up. Liver sonograms were normal in most patients. However, hyperechogenic liver and dystrophic liver were observed in 2 patients (patients 6,11 ) and 1 patient (patient 14), respectively. None of the 15 patients had ultrasonographic evidence for liver dysplasia. Gallstones were observed in 1 patient (patient 3 ). Of note, 2 patients (patients 1 and 4) underwent previously a cholecystectomy for a gallstone disease which did not recur after surgery. Renal cysts initially present in five children with $3 \beta-H S D$ deficiency and no longer detectable after few years of CA therapy remained undetectable at last follow-up. Mean daily CA dose was $6.9 \mathrm{mg} / \mathrm{kg}$ of body weight. Patient 14 still receives UDCA $(200 \mathrm{mg} / \mathrm{d} ; 3 \mathrm{mg} /$ $\mathrm{kg} / \mathrm{d}$ ). Mass spectrometry analysis of urinary bile acids showed that excretion of the atypical metabolites remained low or traces in amount with CA therapy. In the 13 patients with $3 \beta$-HSD deficiency, at initial evaluation and before $C A$ therapy, $3 \beta$-hydroxylated $-\Delta^{5}$ derivatives represented an average of $94 \%$ of total urinary bile acids. These atypical bile acids were dramatically reduced at last evaluation in our previous report after a median follow-up of around 10 years with CA therapy [14]. In the present report and at last evaluation after a median follow-up of 21.9 years with CA therapy, these atypical metabolites were still dramatically reduced by 300 fold (mean: $0.064 \mu \mathrm{mol} / \mathrm{mmol}$ creatinine) and were undetectable in six patients (patients $1,2,7,11,12.13$ ). However, in case of imperfect compliance (patients 6 and 8), we observed an increase in the amount of these atypical BA, which decreased again to their usual levels after improvement of compliance (patient 6). In the two patients with $\Delta^{4}$-3-oxo- $\mathrm{R}$ deficiency, at initial evaluation and before CA therapy, 3-oxo- $\Delta^{4}$ derivatives represented an average of $89 \%$ of total urinary bile acids. These atypical bile acids were highly reduced by 30 fold at last evaluation in our previous report after a follow-up of around 10 years with CA therapy [14]. In the present report and at last evaluation after a follow-up of 20 years with CA therapy, these atypical bile acids remained at similar levels with a reduction of 37 fold $(1.81 \mu \mathrm{mol} /$ mmol creatinine). No problem of compliance was observed in these 2 patients.

Liver fibrosis scored in liver biopsies $(n=3$, patients $10,14$ and 15$)$ or assessed by elastography ( $n=23$ measurements, all patients but patient 2), after 7.5 to more 
Table 2 Fibrosis score before and after cholic acid therapy in 15 patients diagnosed with either a 33-hydroxy- $\Delta 5$-C27-steroid oxidoreductase deficiency (patients 1-13) or a $\Delta 4$-3-oxosteroid 5 $\beta$-reductase deficiency (patients 14-15)

\begin{tabular}{|c|c|c|c|c|c|c|}
\hline \multirow{2}{*}{$\begin{array}{l}\text { Patient } \\
\text { (Family) }\end{array}$} & \multicolumn{6}{|c|}{ Fibrosis score ${ }^{a b}}$, \\
\hline & $\begin{array}{l}\text { before } \\
\text { CA }\end{array}$ & $\begin{array}{l}5-7.5 \text { years with } \\
\text { CA }\end{array}$ & $\begin{array}{l}7.5-<15 \text { years with } \\
\text { CA }\end{array}$ & $15-<20$ years with CA & $\geq 20$ years with $C A$ & \\
\hline $1(\mathrm{~A})$ & $\mathrm{F} 2^{\mathrm{a}}$ & $\begin{array}{l}F 1^{a} \\
5.1 y\end{array}$ & & & $\begin{array}{l}\mathrm{FO}^{\mathrm{b}} \\
\mathrm{TE}=5.4 \mathrm{kPa} \\
22 \mathrm{y}\end{array}$ & \\
\hline $2(B)$ & $\mathrm{F}^{\mathrm{a}}$ & $\begin{array}{l}F 2^{\mathrm{a}} \\
5.4 \mathrm{y}\end{array}$ & & & & \\
\hline $3(C)$ & $\mathrm{F}^{\mathrm{a}}$ & $\begin{array}{l}F 0^{\mathrm{a}} \\
6.5 y\end{array}$ & & & $\begin{array}{l}\mathrm{FO}^{\mathrm{b}} \\
\mathrm{ARFI}=1 \mathrm{~m} / \mathrm{s} \\
22 \mathrm{y}\end{array}$ & \\
\hline 4 (D1) & $\mathrm{F} 4^{\mathrm{a}}$ & $\begin{array}{l}F 3 / F 2^{a} \\
7.2 y\end{array}$ & $\begin{array}{l}\mathrm{F} 2^{\mathrm{b}} \\
\mathrm{TE}=8.3 \mathrm{kPa} \\
14.7 \mathrm{y}\end{array}$ & & $\begin{array}{l}\mathrm{F} 2^{\mathrm{b}} \\
\mathrm{TE}=10 \mathrm{kPa} \\
22 \mathrm{y}\end{array}$ & \\
\hline 5 (D2) & $F 1^{\mathrm{a}}$ & & $\begin{array}{l}\mathrm{FO} 0^{\mathrm{b}} \\
\mathrm{TE}=3.3 \mathrm{kPa} \\
13 \mathrm{y}\end{array}$ & & & \\
\hline $6(E 1)$ & $\mathrm{F}^{\mathrm{a}}$ & $\begin{array}{l}F 1^{\mathrm{a}} \\
5.2 \mathrm{y}\end{array}$ & & $\begin{array}{l}\mathrm{F} 1^{\mathrm{b}} \\
\mathrm{TE}=6.7 \mathrm{kPa} \\
17 \mathrm{y}\end{array}$ & $\begin{array}{l}\mathrm{F}^{\mathrm{b}, \mathrm{f},+} \\
\mathrm{TE}=13 \mathrm{kPa} \\
21 \mathrm{y}\end{array}$ & $\begin{array}{l}\mathrm{F} 1^{\mathrm{b}} \\
\mathrm{TE}=7.8 \mathrm{kPa} \\
24 \mathrm{y}\end{array}$ \\
\hline 7 (E2) & $F 4^{\mathrm{a}}$ & $\begin{array}{l}F 2^{\mathrm{a}} \\
5.3 y\end{array}$ & & & $\begin{array}{l}\mathrm{FO} 0^{\mathrm{b}} \\
\mathrm{TE}=4.8 \mathrm{kPa} \\
21 \mathrm{y}\end{array}$ & \\
\hline $8(\mathrm{~F})$ & $F 3^{\mathrm{a}}$ & $\begin{array}{l}F 1^{\mathrm{a}} \\
5.3 y\end{array}$ & & & $\begin{array}{l}\mathrm{F}^{\mathrm{b},+} \\
\mathrm{SSI}=8.1 \mathrm{kPa}(6.8-9.4) \\
20 \mathrm{y}\end{array}$ & $\begin{array}{l}\mathrm{F} 2^{\mathrm{b},+} \\
\mathrm{SSI}=8.5 \mathrm{kPa}(7.1-9.3) \\
21 \mathrm{y}\end{array}$ \\
\hline $9(\mathrm{G} 1)$ & $F 3^{\mathrm{a}}$ & $\begin{array}{l}F 2^{\mathrm{a}} \\
5.6 \mathrm{y}\end{array}$ & & $\begin{array}{l}\mathrm{FO}^{\mathrm{b}} \\
\mathrm{TE}=4.4 \mathrm{kPa} \\
19 \mathrm{y}\end{array}$ & $\begin{array}{l}\mathrm{FO}^{*} \\
\mathrm{SSI}=4.9 \mathrm{kPa}(4.4-6.1) \\
21 \mathrm{y}\end{array}$ & \\
\hline $10(G 2)$ & $\mathrm{F} 4 / \mathrm{F}^{\mathrm{a}}$ & & $\begin{array}{l}F 2^{a} \\
11.5 y\end{array}$ & $\begin{array}{l}\mathrm{F} 2^{\mathrm{b}} \\
\mathrm{TE}=8.2 \mathrm{kPa} \\
18 \mathrm{y}\end{array}$ & $\begin{array}{l}\mathrm{F} 2^{\mathrm{b}} \\
\mathrm{SSI}=8.2 \mathrm{kPa}(7.9-8.5) \\
21 \mathrm{y}\end{array}$ & \\
\hline $11(H)$ & $\mathrm{F}^{\mathrm{a}}$ & $\begin{array}{l}F 1^{a} \\
5.3 y\end{array}$ & & $\begin{array}{l}\mathrm{FO}^{\mathrm{b}} \\
\mathrm{SSI}=5.4 \mathrm{kPa}(4.4-6.9) \\
19 \mathrm{y}\end{array}$ & & \\
\hline $12(11)$ & $\mathrm{F}^{\mathrm{a}}$ & $\begin{array}{l}F 0^{\mathrm{a}} \\
6.1 \mathrm{y}\end{array}$ & $\begin{array}{l}\mathrm{FO} 0^{\mathrm{b}} \\
\mathrm{TE}=4.6 \mathrm{kPa} \\
13 \mathrm{y}\end{array}$ & $\begin{array}{l}\mathrm{F}^{\mathrm{b}} \\
\mathrm{SSI}=7.7 \mathrm{kPa}(6-9) \\
15.1 \mathrm{y}\end{array}$ & & \\
\hline $13(12)$ & $\mathrm{FO}^{\mathrm{a}}$ & $\begin{array}{l}F 1^{\mathrm{a}} \\
5.5 \mathrm{y}\end{array}$ & $\begin{array}{l}\mathrm{FO} 0^{\mathrm{b}} \\
\mathrm{TE}=4.3 \mathrm{kPa} \\
12 \mathrm{y}\end{array}$ & $\begin{array}{l}\mathrm{FO}^{\mathrm{b}} \\
\mathrm{SSI}=6.7 \mathrm{kPa}(5.6-7.7) \\
15 \mathrm{y}\end{array}$ & & \\
\hline $14(\mathrm{~J} 1)$ & $F 4^{\mathrm{a}}$ & $\begin{array}{l}\mathrm{F} 4 / \mathrm{F}^{\mathrm{a}} \\
5.5 \mathrm{y}\end{array}$ & & $\begin{array}{l}F 3^{\mathrm{a}} \\
16 y\end{array}$ & $\begin{array}{l}\mathrm{FO}^{\mathrm{b}} \\
\mathrm{SSI}=7.3 \mathrm{kPa}(5.7-9.6) \\
20 \mathrm{y}\end{array}$ & \\
\hline $15(J 2)$ & $\mathrm{F}^{\mathrm{a}}$ & $\begin{array}{l}F 2^{a} \\
5.5 y\end{array}$ & & $\begin{array}{ll}\mathrm{F} 1 / \mathrm{F} 2^{\mathrm{a}} & \mathrm{F} 0^{\mathrm{b}} \\
16 \mathrm{y} & \mathrm{SSI}=6.4 \mathrm{kPa}(5.4-7.8) 18 \mathrm{y}\end{array}$ & $\begin{array}{l}\mathrm{FO}{ }^{\mathrm{b}} \\
\mathrm{SSI}=6.9 \mathrm{kPa}(6.5-7.6) \\
20 \mathrm{y}\end{array}$ & \\
\hline Median score & F3 & F1 & F0 & F0.5 & F0 & \\
\hline Range & F0-F4 & F0-F4/F3 & F0-F2 & F0-F3 & F0-F2 & \\
\hline
\end{tabular}

Liver fibrosis was assessed according to Metavir score in liver biopsy specimens ${ }^{a}$, or using the following non invasive methods ${ }^{\mathrm{b}}$ : TE, transient elastography; SSI, supersonic shear imaging; or ARFI, acoustic radiation force impulse. The duration of cholic acid therapy at the time of the assessment of liver fibrosis is indicated below each result. $£$, chronic alcohol intake; +, poor compliance to cholic acid therapy. When in a patient 2 values of fibrosis score were recorded during the same time period, only the more recent value was considered to calculate the median and range values. See patients and methods section for details. CA, cholic acid

than 20 years of CA therapy, showed a marked improvement with disappearance of cirrhosis (patients $4,7,14$ ) (Table 2). The evolution over time of the mean score of fibrosis in the 15 patients is presented in Fig. 1. In the only patient in whom liver fibrosis was not evaluated after 10 years with CA therapy, liver sonogram was 


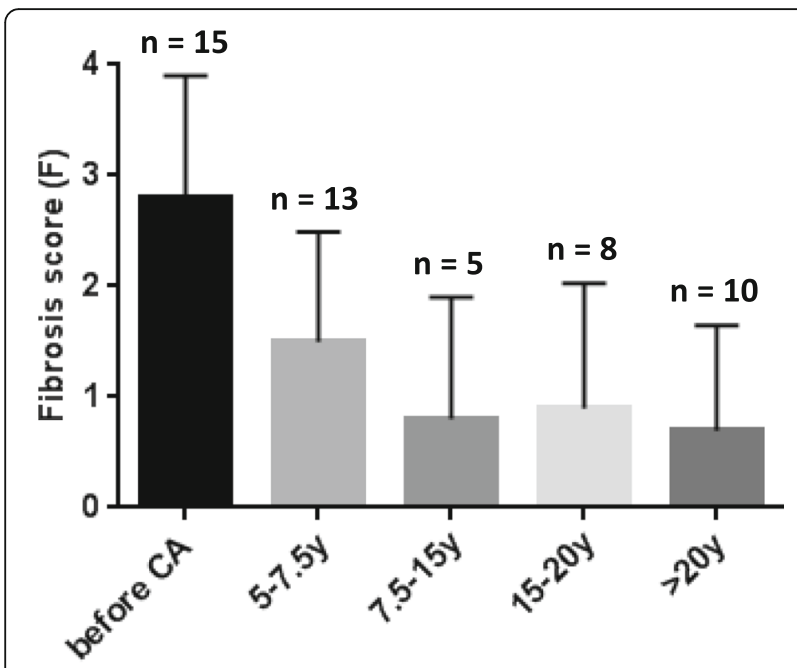

Time with cholic acid therapy

Fig. 1 Effect of long-term oral CA therapy on liver fibrosis in 15 children with $3 \beta$-hydroxy- $\Delta 5$-C27-steroid oxidoreductase deficiency $(n=13)$ or $\Delta 4-3$-oxosteroid $5 \beta$-reductase deficiency $(n=2)$. Fibrosis scores were assessed according to Metavir in liver biopsy specimens or as described in the patients and methods section in cases of assessment using non-invasive methods. See Table 2 for the details of fibrosis scores. Data are presented as mean +/- SD values. When in a patient 2 values of fibrosis score were recorded during the same time period, only the most recent score was considered to calculate the mean $+/-$ SD values

normal at age 27.9 and after 23.6 years with CA (patient 2 , family B). No signs of cholestasis and of inflammatory activity were seen in the biopsy of patient 10 (family G) with $3 \beta$-HSD deficiency performed after 11.5 years of treatment (Fig. 2) and in the two biopsies performed after 16 years of treatment in patients 14 and 15 (Family J) with $\Delta^{4}$-3-oxo-R deficiency (Fig. 3). No patients developed portal hypertension. CA was well tolerated in all patients. Sexual maturation progressed normally in all patients (female and male), including in the two girls who did not yet reach adult age (patients 5 and 13). While treated with CA, four women with $3 \beta$-HSD deficiency (patients $2,7,9,10$ ) and one woman with $\Delta^{4}$ 3-oxo-R deficiency (patient 14) have had nine uneventful pregnancies and one uneventful pregnancy, respectively. During all pregnancies doses of CA were not modified and all newborns were healthy.

At the time of data collection, 5 patients were still students ( 2 at school (college), 3 at university), 8 were employed ( 1 is a nurse, 1 is a teacher, 1 is an assistant in a pet store, 1 is a garbage collector, 1 is a sports educator, 1 is a qualified worker, 2 are engineers) and 2 were housewives. All the patients reported a normal quality of life.

\section{Discussion}

Oral bile acid therapy has been reported to be effective in the treatment of the most common primary bile acid synthesis defects and CA therapy is the recommended therapy in these rare diseases, which are commonly lethal or require liver transplantation if untreated. The aim of this study was to make an update of the follow-up after around 20 years of CA therapy of our previously reported cohort of 15 patients with $3 \beta-H S D$ or $\Delta^{4}-3$-oxo- $\mathrm{R}$ deficiencies [14], most of them having now reached adulthood, and to evaluate the long-term effectiveness and safety of CA therapy. The data confirm the favorable outcome with treatment, mainly the
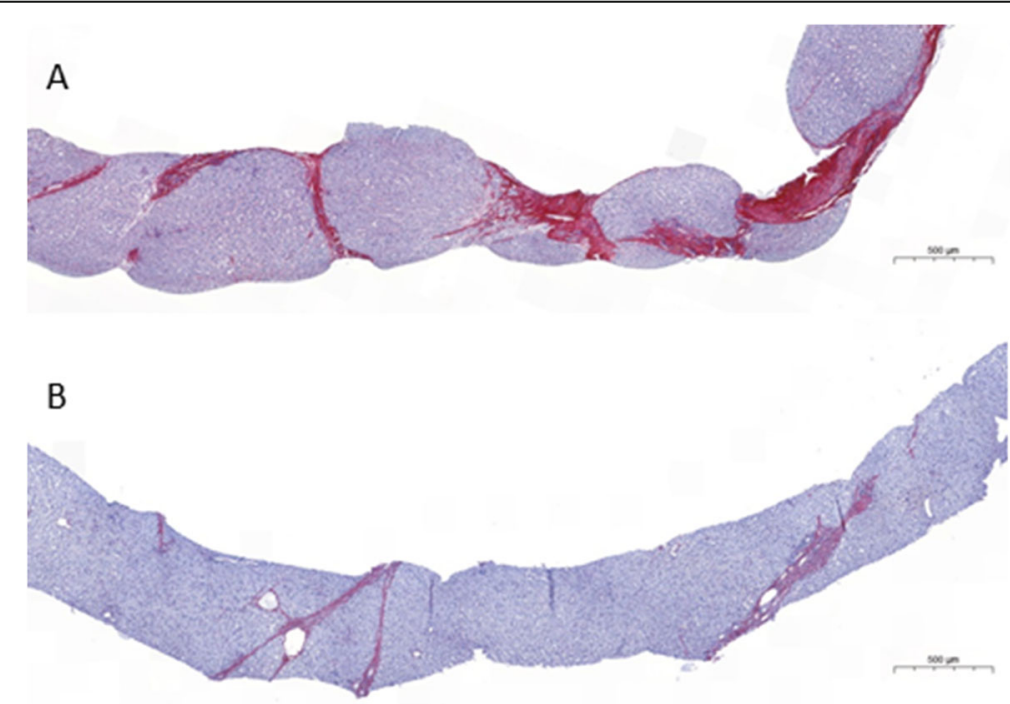

Fig. 2 Initial liver biopsy specimens and the effect of long-term oral CA therapy in patient 10 with 3ß-hydroxy- $\Delta 5$-C27-steroid oxidoreductase deficiency. a Liver histology at onset of CA therapy. $\mathbf{b}$ Liver histology after 11.5 years of CA therapy. See Table 2 for fibrosis scores 


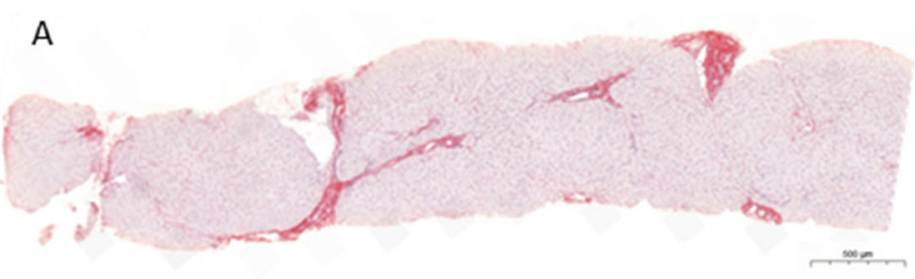

B

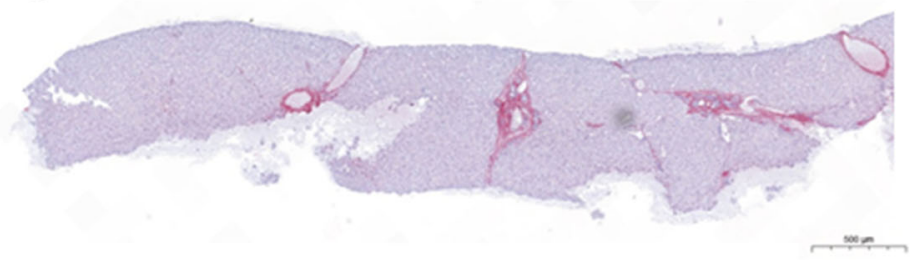

$\mathrm{C}$
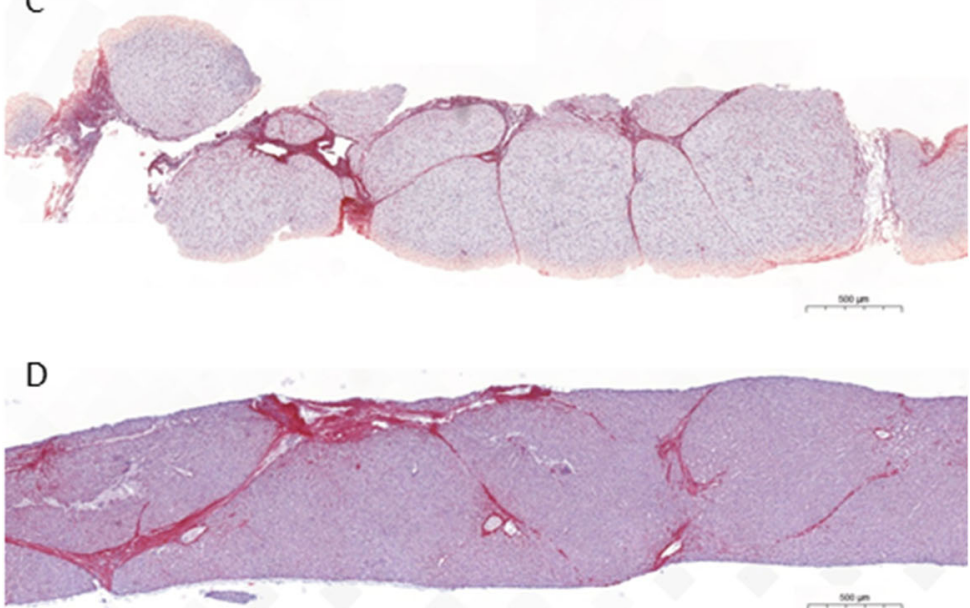

Fig. 3 Evolution during long-term CA therapy of liver pathology in patient 15 (a and $\mathbf{b}$ ) and patient 14 (c and d) with $\Delta 4$-3-oxosteroid 5 $\beta$ reductase deficiency. a Liver histology after 5.5 years of combined UDCA plus CA therapy. $\mathbf{b}$ Liver histology after 16 years of combined UDCA plus CA therapy. $\mathbf{c}$ Liver histology after 5.5 years of CA therapy. $\mathbf{d}$ Liver histology after 16 years of CA therapy. See Table 2 for fibrosis scores

decrease in liver fibrosis, and show that CA therapy is safe and should guarantee a normal quality of life during adulthood.

The 15 children with a genetic defect in primary bile acid synthesis received oral CA treatment for a median period of 21.4 years. With CA therapy, the long-term outcome and the biochemical control of the patients were excellent. All patients are alive with their native liver, with normal findings on physical examination, unless hypo/areflexia in 4 patients being the irreversible consequence of prolonged vitamin E deficiency before disease diagnosis. Also, all patients had normal serum liver biochemistry tests and the excretion of the atypical metabolites of bile acids remained low or traces in amount, signing a good metabolic control of the primary bile acid synthesis defects with CA therapy. However, for patients with $3 \beta$-HSD deficiency, one study suggested that tandem mass spectrometry could allow a more accurate quantification of $3 \beta$-hydroxylated- $\Delta^{5}$ derivatives [25]. Most patients had normal liver ultrasonography and 4 patients had minor ultrasonographic liver abnormalities. In all patients serum alphafetoprotein level was persistently normal and none of the patients developed hepatocellular carcinoma. Liver fibrosis scored in liver biopsies and/or by elastography in 14 patients, after 10 to 24 years of CA therapy, seems to confirm in the long-term the previously reported marked improvement of fibrosis with time compared to initial scores. Of note we observed a disappearance of cirrhosis in 3 patients, as it has been reported in other liver diseases [26]. Among the non-invasive methods of measuring liver stiffness that is supposed to mainly result from fibrosis, TE, SSI and ARFI technologies have shown good accuracy for the detection and quantification of liver fibrosis in adult series [22-24, 27]. These series concerned patients with different types of liver diseases, including patients with chronic 
cholestasis but no patients with cholestasis due to a primary defect in bile acid synthesis were reported in these series. Therefore, the absence of previous validation of these technologies to evaluate liver fibrosis in the patients reported here may represent a limitation in the interpretation of the data. Only two patients had a worsening of fibrosis score after 20 years of therapy (patients 6 (E1) and $8(\mathrm{~F})$ ). In patient 6 , this was transient and likely due to chronic alcohol intake and poor compliance to therapy since the age of 18 years; fibrosis score improved after good compliance and alcoholic withdrawal were achieved. In patient 8 , worsening of fibrosis score can be explained by a chronic imperfect compliance.

The study confirmed the safety of CA therapy, including during pregnancy. No serious adverse events were observed with a cumulative duration of treatment of more than 300 patient-years and five women treated at therapeutic/physiologic doses have given birth to 10 healthy newborns. This shows that CA is unlikely to be embryotoxic when taken at therapeutic (physiologic) doses during pregnancy. Last but not least, all the patients had a social status and a professional activity similar to the general population.

\section{Conclusions}

All in all, these data show that oral CA therapy is a safe and effective long-term treatment of the most common primary bile acid synthesis defects. CA therapy allows affected children to reach adulthood in good health condition without the need for a liver transplantation. Provided a successful transition and a follow-up during adulthood performed by a specialized hepatologist, it is likely that CA therapy will guarantee to patients, including patients diagnosed at adult age, a normal quality of life throughout all their lifetime [28-30].

\section{Abbreviations

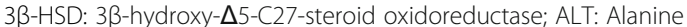 aminotransferase; ARFI: Acoustic radiation force impulse; CA: Cholic acid; CDCA: Chenodeoxycholic acid; DCA: Deoxycholic acid; FAB-MS: Fast atom bombardment/mass spectrometry; GC-MS: Gas chromatography/mass spectrometry; GGT: Gamma-glutamyl transferase; SSI: Supersonic shear imaging; TE: Transient elastography; UDCA: Ursodeoxycholic acid; $\Delta$ 4-3-oxo-R: $\Delta 4$-3-oxosteroid 5 $\beta$-reductase}

\section{Acknowledgements}

We thank Dr. B. Soto (Department of Pediatrics, Hôpital de Troyes, Troyes, France) and Dr. M. Sciveres (Department of Pediatrics, ISMETT, Palermo, Italy) for their help in the follow-up of patients 4, 5, 12 and 13 and AMFE ("Association Maladies Foie Enfants", Malakoff, France), MLD (Monaco Liver Disorder, Monaco), and foundation Rumsey-Cartier (Geneva, Switzerland) for their support.

\section{Availability of data and materials}

The datasets used and/or analysed during the current study are available from the corresponding author on reasonable request.

\section{Authors' contributions}

EG, EJ: study design and concept, interpretation of data; LM, AM, SFA, AD, JC, $\mathrm{DH}, \mathrm{CG}, \mathrm{SH}$ : acquisition, analysis, interpretation and drafting; AMT: technical support; All authors: critical revision and intellectual input. All authors read and approved the final manuscript

\section{Ethics approval and consent to participate}

The study complied with the Declaration of Helsinki. For the treatment period from 1993 to August 2007, the study was approved by the Ethics Committee of Bicêtre Hospital (Comité de Protection des Personnes, Hôpital Bicêtre, Le Kremlin-Bicêtre, France) and written informed consent was obtained from parents prior to enrollment, as previously reported [14]. Since August 2007 to September 2013, patients benefited from a "Autorisation Temporaire d'Utilisation" delivered for each patient by the "Agence Nationale de Sécurité du Médicament et des Produits de Santé (France)". Thereafter, the European Commission granted a marketing authorisation valid throughout the European Union for Orphacol on September 2013 [21]. Therefore, for the 10 year period from August 2007 to 2017 which represents the basis of the study, consent to participate was not needed.

\section{Consent for publication}

Not applicable.

\section{Competing interests}

EJ consulted for laboratory CTRS (France). EG received support for travel from CTRS, Alexion, Spindler Mayoli, Albireo. The other authors reported no conflict of interest

\section{Publisher's Note}

Springer Nature remains neutral with regard to jurisdictional claims in published maps and institutional affiliations.

\section{Author details}

${ }^{1}$ Pediatric Hepatology and Pediatric Liver Transplantation Unit, National Reference Centre for rare pediatric liver diseases and Filfoie, Hôpital Bicêtre, Assistance Publique-Hôpitaux de Paris, Paris, France. ${ }^{2}$ Faculty of Medicine Paris - Sud, University Paris - Sud / Paris - Saclay, Paris, France. ${ }^{3}$ INSERM UMR-S1174 and Hepatinov, University Paris - Sud / Paris - Saclay, Orsay, France. ${ }^{4}$ University of Trieste, Trieste, Italy. ${ }^{5}$ Pediatric Radiology Unit, Hôpital Bicêtre, Assistance Publique - Hôpitaux de Paris, Paris, France. ${ }^{6}$ Department of Pediatrics, Hôpital Sud, Rennes, France. ${ }^{7}$ Hepatology Unit, Hôpital Foch, and Hôpital Beaujon, Assistance Publique - Hôpitaux de Paris, Paris, France. ${ }^{8}$ Pathology Unit, Hôpital Bicêtre, Assistance Publique - Hôpitaux de Paris, Paris, France. ${ }^{9}$ Pharmacy Unit, Hôpital Bicêtre, Assistance Publique - Hôpitaux de Paris, Paris, France. ${ }^{10}$ Groupe Hospitalier Paris Saint-Joseph, Paris, France.

${ }^{11}$ Service d'Hépatologie et de Transplantation Hépatique Pédiatriques, Hôpital Bicêtre, 78, rue du Général Leclerc, Le Kremlin-Bicêtre, France.

Received: 19 January 2018 Accepted: 24 September 2018

Published online: 29 October 2018

References

1. Clayton PT, Leonard JV, Lawson AM, Setchell KD, Andersson S, Egestad B, et al. Familial giant cell hepatitis associated with synthesis of 3 beta, 7 alpha-dihydroxy-and 3 beta,7 alpha, 12 alpha-trihydroxy-5-cholenoic acids. J Clin Invest. 1987:79:1031-8.

2. Setchell KD, Suchy FJ, Welsh MB, Zimmer-Nechemias L, Heubi J, Balistreri WF. Delta 4-3-oxosteroid 5 beta-reductase deficiency described in identical twins with neonatal hepatitis. A new inborn error in bile acid synthesis. J Clin Invest. 1988:82:2148-57.

3. Schwarz M, Wright AC, Davis DL, Nazer H, Björkhem I, Russell DW. The bile acid synthetic gene 3beta-hydroxy-Delta(5)-C(27)-steroid oxidoreductase is mutated in progressive intrahepatic cholestasis. J Clin Invest. 2000;106: $1175-84$.

4. Cheng JB, Jacquemin E, Gerhardt M, Nazer H, Cresteil D, Heubi JE, et al. Molecular genetics of 3beta-hydroxy-Delta5-C27-steroid oxidoreductase deficiency in 16 patients with loss of bile acid synthesis and liver disease. J Clin Endocrinol Metab. 2003;88:1833-41.

5. Lemonde HA, Custard EJ, Bouquet J, Duran M, Overmars H, Scambler PJ, et al. Mutations in SRD5B1 (AKR1D1), the gene encoding delta(4)-3oxosteroid 5beta-reductase, in hepatitis and liver failure in infancy. Gut. 2003;52:1494-9. 
6. Gonzales E, Cresteil D, Baussan C, Dabadie A, Gerhardt MF, Jacquemin E. SRD5B1 (AKR1D1) gene analysis in delta(4)-3-oxosteroid 5beta-reductase deficiency: evidence for primary genetic defect. J Hepatol. 2004;40:716-8.

7. Jahnel J, Zöhrer E, Fischler B, D'Antiga L, Debray D, Dezsofi A, et al. Attempt to determine the prevalence of two inborn errors of primary bile acid synthesis: results of a European survey. J Pediatr Gastroenterol Nutr. 2017;64:864-8.

8. Russell DW. The enzymes, regulation, and genetics of bile acid synthesis. Annu Rev Biochem. 2003;72:137-74.

9. Clayton PT. Disorders of bile acid synthesis. J Inher Metab Dis. 2011;34 593-604.

10. Setchell KD, Heubi JE. Defects in bile acid biosynthesis--diagnosis and treatment. J Pediatr Gastroenterol Nutr. 2006;43(Suppl 1):S17-22.

11. Stieger B, Zhang J, O'Neill B, Sjovall J, Meier PJ. Differential interaction of bile acids from patients with inborn errors of bile acid synthesis with hepatocellular bile acid transporters. Eur J Biochem. 1997;244:39-44.

12. Jacquemin E, Setchell KD, O'Connell NC, Estrada A, Maggiore G, Schmitz J, et al. A new cause of progressive intrahepatic cholestasis: 3 betahydroxy-C27-steroid dehydrogenase/isomerase deficiency. J Pediatr. 1994;125:379-84.

13. Daugherty CC, Setchell KD, Heubi JE, et al. Resolution of liver biopsy alterations in three siblings with bile acid treatment of an inborn error of bile acid metabolism (delta 4-3-oxosteroid 5 beta-reductase deficiency). Hepatology. 1993;18:1096-101.

14. Gonzales E, Gerhardt MF, Fabre M, Setchell KD, Davit-Spraul A, Vincent I, et al. Oral cholic acid for hereditary defects of primary bile acid synthesis: a safe and effective long-term therapy. Gastroenterology. 2009;137:1310-20.

15. Riello L, D'Antiga L, Guido M, Alaggio R, Giordano G, Zancan L. Titration of bile acid supplements in 3beta-hydroxy-Delta 5-C27-steroid dehydrogenase/ isomerase deficiency. J Pediatr Gastroenterol Nutr. 2010;50:655-60.

16. Subramaniam P, Clayton PT, Portmann BC, Mieli-Vergani G, Hadzić N. Variable clinical spectrum of the most common inborn error of bile acid metabolism--3beta-hydroxy-Delta 5-C27-steroid dehydrogenase deficiency. J Pediatr Gastroenterol Nutr. 2010;50:61-6.

17. Morgan NV, Hartley JL, Setchell KD, Simpson MA, Brown R, Tee L, et al. A combination of mutations in AKR1D1 and SKIV2L in a family with severe infantile liver disease. Orphanet J Rare Dis. 2013;8:74.

18. Al-Hussaini AA, Setchell KDR, AlSaleem B, Heubi JE, Lone K, Davit-Spraul A, et al. Bile acid synthesis disorders in Arabs: a 10-year screening study. J Pediatr Gastroenterol Nutr. 2017;65:613-20.

19. Heubi JE, Bove KE, Setchell KDR. Oral Cholic acid is efficacious and well tolerated in patients with bile acid synthesis and Zellweger Spectrum disorders. J Pediatr Gastroenterol Nutr. 2017;65:321-6.

20. US Food \& Drug Administration. Available at: https://www.accessdata.fda. gov/scripts/cder/daf/index.cfm?event=overview.process\&varApplNo= 205750\#collapseApproval.

21. European Medicine Agency. Available at: http://www.ema.europa.eu/ema/ index.jsp?curl=pages/medicines/human/orphans/2009/11/human_orphan_ 000338.jsp\&mid=WC0b01ac058001d12b.

22. Corpechot C, Gaouar F, El Naggar A, Kemgang A, Wendum D, Poupon R, et al. Baseline values and changes in liver stiffness measured by transient elastography are associated with severity of fibrosis and outcomes of patients with primary sclerosing cholangitis. Gastroenterology. 2014;146: 970-9.

23. Feng JC, Li J, Wu XW, Peng XY. Diagnostic accuracy of SuperSonic shear imaging for staging of liver fibrosis: a meta-analysis. J Ultrasound Med. 2016; 35:329-39.

24. Jain V, Dixit R, Chowdhury V, Puri AS, Gondal R. Can acoustic radiation force impulse elastography be a substitute for liver biopsy in predicting liver fibrosis? Clin Radiol. 2016;71:869-75

25. Zhang W, Jha P, Wolfe B, Gioiello A, Pellicciari R, Wang J, et al. Tandem mass spectrometric determination of atypical $3 \beta$-hydroxy- $\Delta 5$-bile acids in patients with $3 \beta$-hydroxy- $\Delta 5$-C27-steroid oxidoreductase deficiency: application to diagnosis and monitoring of bile acid therapeutic response. Clin Chem. 2015;61:955-63.

26. Bortolotti F, Guido M. Reversal of liver cirrhosis: a desirable clinical outcome and its pathogenic background. J Pediatr Gastroenterol Nutr. 2007;44:401-6.

27. Corpechot C. Utility of non-invasive markers of fibrosis in Cholestatic liver diseases. Clin Liver Dis. 2016;20:143-58.
28. Fischler B, Bodin K, Stjernman H, Olin M, Hansson M, Sjövall J, et al. Cholestatic liver disease in adults may be due to an inherited defect in bile acid biosynthesis. J Intern Med. 2007;262:254-62.

29. Molho-Pessach V, Rios JJ, Xing C, Setchell KD, Cohen JC, Hobbs HH. Homozygosity mapping identifies a bile acid biosynthetic defect in an adult with cirrhosis of unknown etiology. Hepatology. 2012;55:1139-45.

30. Joshi D, Gupta N, Samyn M, Deheragoda M, Dobbels F, Heneghan MA. The management of childhood liver diseases in adulthood. J Hepatol. 2017;66:631-44

\section{Ready to submit your research? Choose BMC and benefit from:}

- fast, convenient online submission

- thorough peer review by experienced researchers in your field

- rapid publication on acceptance

- support for research data, including large and complex data types

- gold Open Access which fosters wider collaboration and increased citations

- maximum visibility for your research: over $100 \mathrm{M}$ website views per year

At BMC, research is always in progress.

Learn more biomedcentral.com/submissions 